\title{
When good neighbours become good friends: observing small scale structures in fish aggregations using multibeam sonar
}

\author{
Francois Gerlotto $^{1, a}$, Emma Jones ${ }^{2}$, Nicolas Bez ${ }^{1}$ and David G. Reid ${ }^{3}$ \\ 1 IRD, CRH, avenue Jean Monnet, 34203 Sète, France \\ 2 National Institute of Water and Atmospheric Research Ltd. (NIWA), 269 Khyber Pass Road, Newmarket, Auckland 1023, PO Box 109-695, \\ Newmarket, Auckland 1149, New Zealand \\ 3 Marine Institute, Rinville, Oranmore, Co. Galway, Ireland
}

Received 10 July 2009; Accepted 20 May 2010

\begin{abstract}
Converging results in different scientific fields (behavioural ecology, fisheries biology, acoustic tagging, fisheries acoustics, behavioural modelling) suggest the existence of "micro-groups" inside fish schools. These would comprise a few (5-10) fish maintaining contact during a period long enough to allow individuals to recognise each other. It is hypothesised that they would prefer to share the space with familiar rather than anonymous conspecifics. To evaluate whether acoustic methods could be used to recognise "micro-structures" inside fish schools and help test the "micro-group" hypothesis we analysed acoustic data from anchovy schools off Peru, and gadoids in the North Sea. Data collection used a multibeam sonar (Reson SeaBat 6012). In the Peruvian case study, the sonar was mounted set horizontally on a drifting research vessel and the internal structure of the schools of anchovies was analysed, although individual fish could not be discriminated. In the North Sea case study, the sonar was orientated vertically above a demersal trawl to allow observation of individual fish entering the trawl. Geostatistical analyses were used to evaluate the existence of small spatial structures in anchovy schools. In these schools, "micro-structures" with a scale as small as $0.5 \mathrm{~m}$ were observed acoustically. For the gadoids nearest neighbour distance (NDD) measurements were carried out, suggesting that the fish aggregated in small groups ( 2 to 25 individuals, with an average of 3.7 fish per group) in the trawl catches. The perspectives and limitations of these results are discussed.
\end{abstract}

Key words: Anchovy / Behaviour / Geostatistics / Multibeam sonar / Fish school / Spatial structure / Micro-group

Résumé - Des résultats convergents dans différents domaines scientifiques (écologie, éco-éthologie, marquage acoustique, acoustique halieutique, modélisation du comportement) suggèrent l'existence de "microgroupes » à l'intérieur des bancs de poissons. Ces structures seraient composées d'un petit nombre d'individus (5 à 10) restant en contact pendant une période assez longue pour leur permettre de se reconnaître entre eux. L'hypothèse suggérée par cette observation est qu'il est plus efficace pour des poissons grégaires de partager l'espace avec des individus familiers plutôt qu'anonymes. Afin d'évaluer si l'acoustique peut être employée pour identifier des «microstructures » dans les bancs, qui seraient la représentation spatiale de ces «microgroupes », nous avons analysé des données acoustiques enregistrées à partir de sonars multifaisceaux (Reson SeaBat 6012) sur des bancs d'anchois au Pérou, et sur des gadidés en mer du Nord. Dans le cas des anchois, le sonar était monté horizontalement le long d'un navire dérivant et la structure interne des bancs d'anchois a été analysée en termes de densités ponctuelles (par éléments ou pixels de $0,01 \mathrm{~m}^{2}$ ), les poissons ne pouvant pas être identifiés individuellement. Dans le cas de la mer du Nord, le sonar a été orienté verticalement audessus d'un chalut démersal pour permettre l'observation individuelle des poissons entrant dans le chalut. Des modèles géostatistiques ont mis en évidence l'existence de microstructures spatiales dans les bancs d'anchois. Dans ces bancs, on a observé des microstructures de diamètre allant de 0,4 à $5 \mathrm{~m}$. Pour les gadidés, les mesures de distance au plus proche voisin qui ont été effectuées, laissent penser que les poissons s'agrègent en petits groupes d'individus ( 2 à 25 , avec une moyenne de 3,7 poissons par groupe) dans le chalut. Les perspectives et les limitations de ces résultats sont discutées.

\section{Introduction}

Fish schools have been studied and analyzed using a wide number of methods, and models have been designed, particularly individual-based models (IBM), to elucidate the behaviour of the individual fish (Huth and Wissel 1992; Parrish et al. 2002; Couzin et al. 2002; Vabø and Nøttestad 1997). Based on IBMs, behavioural rules were described for

a Corresponding author: francois.gerlotto@ird.fr 
inter-individual distances and orientation of individuals with respect to each other, as well as other behaviours. Mirabet et al. (2007) stated that in IBM simulations "all individuals are identical and move according to the same rules so as to ensure that grouping appears and maintains itself without any pre-determined leader". In the wild, fish can often form large schools, comprising thousands or millions of individuals. These schools have been shown in some cases to have internal variations in structure, including vacuoles (Fréon et al. 1992) and nuclei (Gerlotto and Paramo 2003), holes and dense patches. Behavioural mechanisms (rules), involving a range of inter-individual reactions, have been described to help explain this substructuring (Soria et al. 2007).

In all these rule based studies on collective behaviour there was an implicit assumption that fish in a school are strictly anonymous, i.e. each individual fish considers all other fish in the school as identical; "Relatedness to, or knowledge of, neighbors may be minimal, and the group is maintained through collective individual responses" (Parrish and Edelstein-Keshet 1999). However, Viscido et al. (2005) reported that increasing the number of individuals that a single fish has to take into account for maintaining Nearest Neighbour Distance (NND) to more than 6-8 individuals in an IBM resulted in non-realistic spatial structures. Mirabet et al. (2007) also noted that "models of animal grouping should follow several constraints among which is a low number of neighbours".

Zaferman (2005) was the first to suggest the existence of small cohesive structures inside fish schools using detailed acoustic data. His hypothesis was that fish within most of the schools were not evenly distributed, but aggregated into small spatial structures of between three and ten individuals. He described these structures as "micro-groups".

Similar observations have been made on birds flying in large flocks. Ballerini et al. (2008) observed and measured the positions of individuals inside a large (above 1500 individuals) flock of European starlings Sturnus vulgaris. They found that individuals were not organized as one would expect based on strictly geometrical rules (inter-individual reactions within a given distance) but appeared to follow topological rules, where a fixed number of individuals react in relation to each other regardless of the distance between them. The average number of individuals interacting was found to be around six.

Research over the last decade suggests that the assumption of individual anonymity may not always be true. The existence of cognitive function within small groups of fish has been found in a range of studies (see Brown et al. 2006 for a review). This leads to the hypothesis that small groups of animals that are familiar with each other may be found within, larger, natural schools and could represent an important additional organizational driver. This phenomenon was described as "small world networks" by Brown et al. (2006). The principle characteristic of such groups would be that the individuals would stay associated longer than would be expected on a simple geometric rule basis, and would hence be expected to become "familiar" with each other. An important question would be whether such structures would also persist through the diel pattern of school aggregation/dispersion (Fréon et al. 1996).
Based on the above, we suggest the possibility of "microstructures" and "micro-groups" within fish schools. Microstructures would be where schools show internal structuring only on the basis of inter individual geometric rules, these would be expected to be transient and ephemeral. Microgroups would be where some cognitive relationships between individuals exists, these would tend to be more persistent than micro-structures. The first step for describing micro-groups would be to confirm the existence of micro-structures in a large school. Without micro-structures, it would be unlikely for the "familiarity" between individuals to develop that would be necessary for the formation of micro-groups.

Most previous studies of detailed behaviour of fish within schools have been carried out on small schools (less than one hundred fish) under experimental conditions. Demonstration of micro-structures inside schools and of measuring their characteristics in situ has hitherto been impossible. However, multibeam sonar, which provides a resolution down to the scale of a few centimetres, and can be used to discriminate individual fish, may be able to bridge this gap.

This paper then has two main objectives. Firstly, we set out to demonstrate the potential for high resolution multi-beam imaging sonar to discriminate fine scale 3D structure within fish schools. This was tested on anchovy Engraulis ringens schools in Peru, and on groups of gadoids during trawl capture in the North Sea. The second objective was to use this technology to characterise these micro-structures (mainly for the anchovy). The findings are discussed in terms of the potential for micro-groups and cognitive aggregation within fish schools

\section{Materials and methods}

The first data set used in the analysis was for anchovy schools, collected during a co-operative acoustic survey carried out with the Marine Institute of Peru (IMARPE). For this data set we followed the analytical approach described by Gerlotto et al. (2006), which used a geostatistical analysis (Rivoirard et al. 2000) of the acoustic data recorded from a horizontally orientated multi-beam sonar mounted on a drifting vessel. Small scale ( $40 \mathrm{~cm}$ diameter) spatial structure was observed within this school

Anchovy are a relatively small schooling species, the other data set we examined was for larger gadoid fish in the North Sea. These fish do not form the tight schools observed for anchovy but do still aggregate, albeit more loosely, and without the close geometric patterning. The fish were recorded using a multi-beam sonar as they entered a trawl net under bottom trawl survey conditions. The aim with these data was to determine if the fish were entering the net randomly or in groups. Any observation of groups would tend to suggest micro-structuring.

\subsection{Peruvian anchovy}

Data on schools was recorded using a multibeam sonar (Reson SeaBat 6012 ), with 60 beams of $1.5^{\circ} \times 22^{\circ}$, covering a total sector of $90^{\circ}$ in the horizontal plan, with range set at $50 \mathrm{~m}$. The survey was carried out off the coast of Lima in April, 


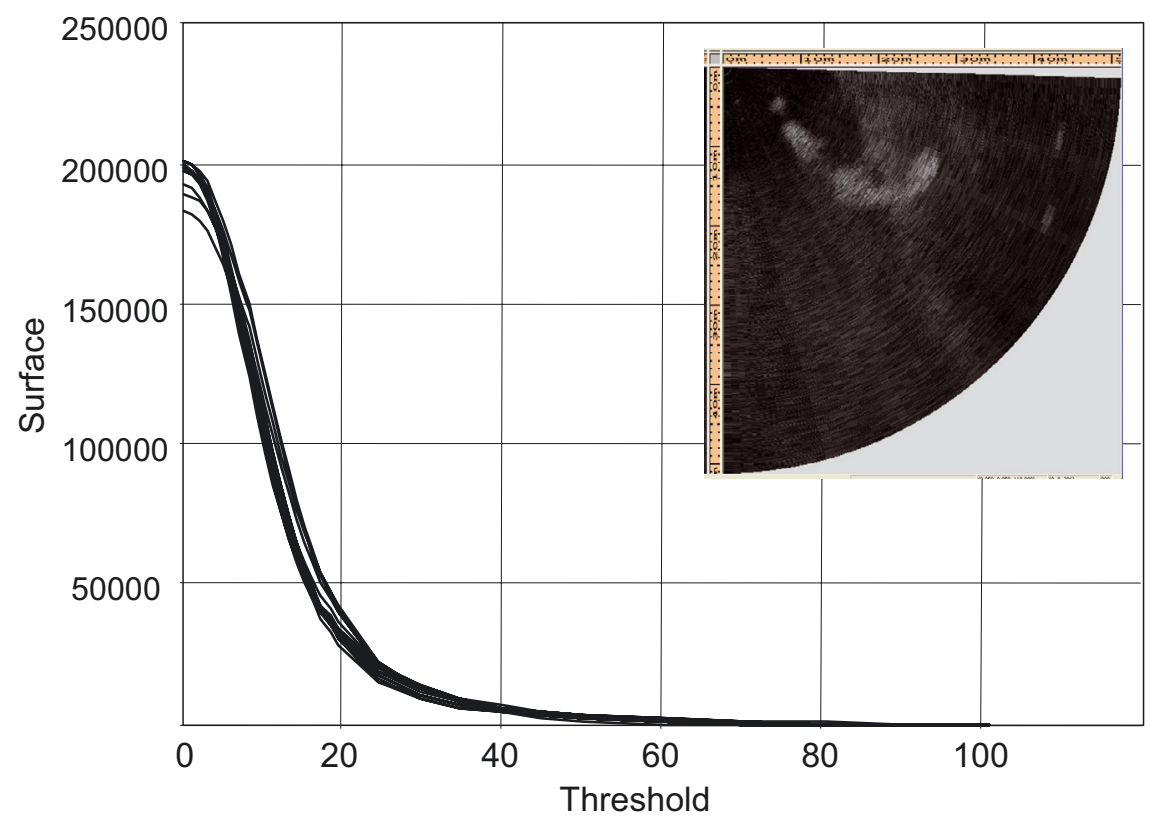

Fig. 1. Curves of the relationships between surface and threshold for a set of 16 images in a sequence (\#149, April, $4^{\text {th }}, 2003$, off Lima) on a school crossing the observed area. The surface corresponds to the sum of pixels in the images that had an acoustic density over the threshold. In the upper right corner, is an image of ping 207, from the same school. The vessel was located on the upper left corner; the range was $50 \mathrm{~m}$. The two dimensions are horizontal dimensions. Densities in each pixel are expressed in grey levels (256 step scale).

2003 aboard the R.V. SNP2 while drifting. The sonar was located on the port side, with its central axis perpendicular to the vessel axis. We selected one school for analysis which was observed on the sonar for two minutes and 45 seconds. This school was selected because of its relatively low biomass, its location very close to the surface with limited height and because no predators were observed feeding on it or in the area. Fish were also sampled using a pelagic trawl and mean standard length was measured as $15 \mathrm{~cm}$ (Bertrand et al. 2008).

To ensure consistency of results and conclusions, we compared the results for the selected school with a series of 11 other schools observed under the same conditions during the same experiment. Data were recorded at a ping rate of $3.5 \mathrm{~s}^{-1}$. Data were digitized in $10 \mathrm{~cm}$ pixels along each beam (510 pixels for each beam). The pulse length was set at 0.06 millisecond, represents $4.5 \mathrm{~cm}$. indicating that $10 \mathrm{~cm}$ pixels were appropriate as elementary sampling units. Acoustic densities were recorded in relative units using a grey scale of 256 steps, from black (density $=0$ ) to white (maximum density $=255$ ). Although these could theoretically be transformed into absolute density values using a conversion factor, this was not done as the system was not calibrated and no target strength (TS) information for this species, frequency and orientation was available. For the purpose of this study, relative density was sufficient. Figure 1 shows one image recorded from the school (Gerlotto and Paramo 2003). In order to avoid bias in the data structure, such as those described by Gerlotto et al. (2006) at short ranges, for each beam of a given image, we calculated the variogram of the raw polar acoustic data in one direction parallel to the beam axis. Finally, we computed a mean unidirectional variogram for the 60 beams. Variogram calculation was carried out in $\operatorname{Surfer}^{\complement} 8$. A set of 21 images were selected from the passage over the school. The 11 other schools of the test series represent the longest recordings observed and from each school we selected the clearest image, and applied the same protocol.

Variograms inside the school area were calculated using a density threshold of 20 (values below the threshold were excluded). This threshold was based on a preliminary study where the density distribution inside the images was calculated (Fig. 1) and it was considered that fish school data were likely to appear at densities above 20. Thus, applying 20 as a threshold, was a way to ensure working with actual school data. The drawback is that some fish and fish groups may be present inside the "background noise" area. To evaluate this effect, variograms were calculated setting the maximum threshold successively at 5, 10, 12, 18 and 20. For the test series of schools we selected a slightly lower threshold at 15 , to try to include all the fish aggregations inside and outside the school.

\subsection{Gadoids from the North Sea}

This data set was extracted from video recordings of multibeam sonar observations of gadoid fish (mainly haddock (Melanogrammus aeglefinus), whiting (Merlangius merlangus) and poor cod (Trisopterus minutus) entering a demersal trawl (Jones et al. 2001). The large size of these fish $(20-50 \mathrm{~cm})$ allowed individual observations to be taken and the data provides the $3 \mathrm{D}$ location of each individual entering the net. Fishing took place east of Orkney during November 2003. A standard GOV sampling trawl was used and was towed at 3.5 knots for $30 \mathrm{~min}$. A remotely operated TV vehicle (RCTV) was positioned above the centre of the trawl and immediately behind the groundgear. A multi-beam sonar 


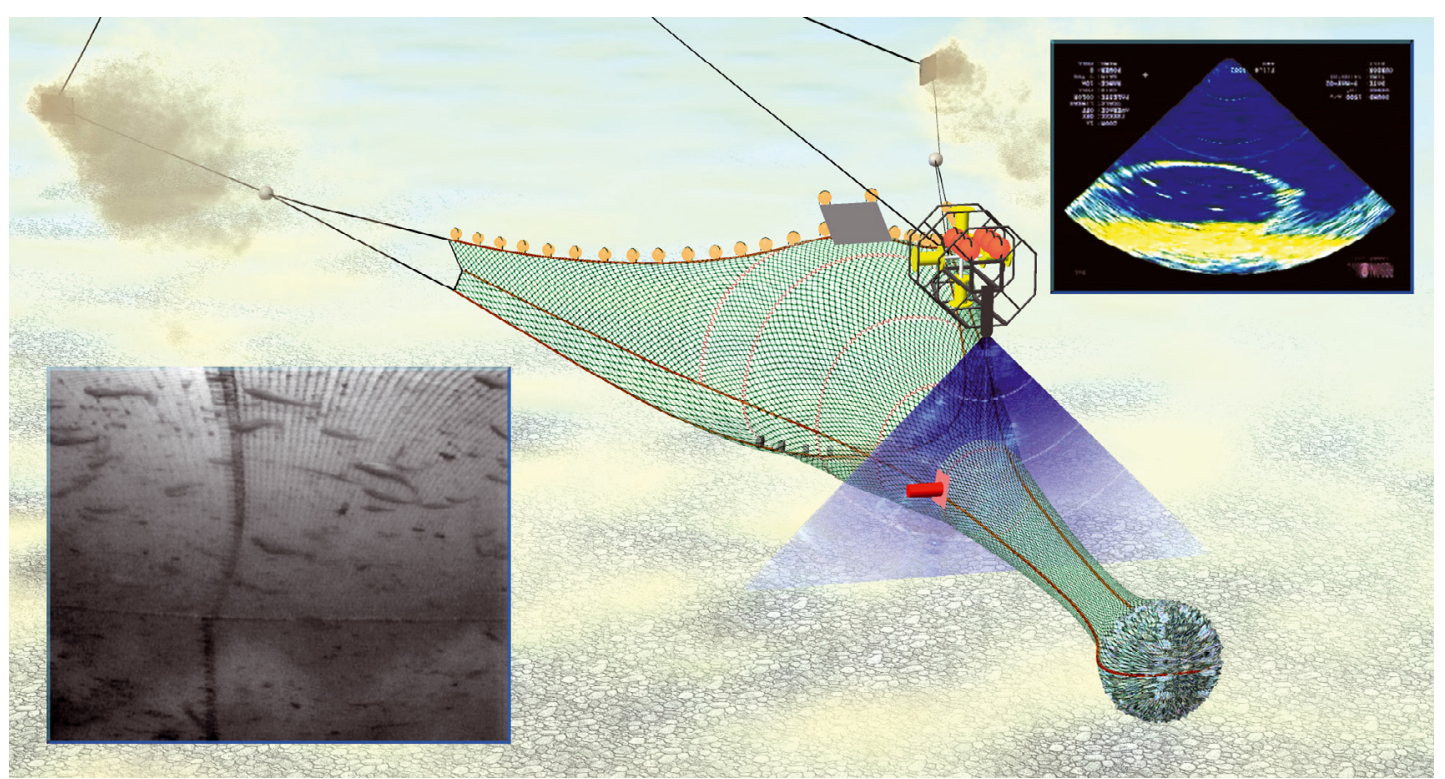

Fig. 2. Diagram of the utilisation of multibeam sonar for observation of fish entering a GOV ("grande ouverture verticale" trawl). Individuals were recorded on the sonar image of the trawl (upper corner right) and located in 3D.

(Reson SeaBat 6012) was mounted on the RCTV orientated to view a $90^{\circ}$ slice through the net below (Fig. 2). Low light cameras were mounted on the net to provide a qualitative indication of species identification where visibility permitted.

The video output from the sonar for each haul was recorded and analysed to record the time and position of the individual fish echo traces as well as the vertical and horizontal dimensions of the trawl at that time. Where dense shoals of fish were observed entering the net (identified as typically sandeel Ammodytes sp., and sprat Sprattus sprattus using video footage), accurate echo counting was not attempted. These were labelled separately and excluded from this analysis. For the purposes of this exercise, we selected a series of hauls where gadoids were the predominant species (haddock, poor cod and whiting).

Two measurements of neighbour distance were used: the "following neighbour distance" (FND), which is the distance between fish $n$ and fish $n+1$; and the "nearest neighbour distance" (NND) where the smallest distance between a fish and its neighbours is selected. This last measurement may produce duplicate values when fish $n$ is the second or the last one of a group: NND for fish $n$ and fish $n-1$ or NND for fish 1 and 2 can be the same. Unlike FND, NND do not take into account the longer distances between the last fish of a group and the first one of the following group. The NND histogram was calculated on this set of values. FNDs are used to count the number of fish in a group. When FND is superior to the "maximum interaction distance" (MID) at which fish are too far away from each other to develop interactive reactions, then fish $n$ is the last one of a group and fish $n+1$ belongs to another group or is solitary.

In this dataset, the geometric location of a fish is expressed through the $x$ and $y$ co-ordinates on the screen, taking the intersection of axes R1 (vertical net diameter) and R2 (horizontal net diameter) as spatial references; and the $z$ distance, calculated from elapsed time by taking an average trawl speed of
Table 1. Range (in lags) of the structures encountered in the 11 schools sampled.

\begin{tabular}{cccccc}
\hline & & \multicolumn{2}{c}{ Spherical 1 } & \multicolumn{2}{c}{ Spherical 2 } \\
\cline { 3 - 6 } School & Nugge & & & & \\
Nb & & Range & Sill & Range & Sill \\
\hline 42 & 300 & 5 & 350 & 45 & 550 \\
43 & 150 & 4 & 80 & 35 & 160 \\
54 & 90 & 11 & 85 & - & - \\
65 & 130 & 6 & 75 & - & - \\
79 & 320 & - & - & 37 & 110 \\
80 & 600 & - & - & 43 & 220 \\
92 & 95 & 5 & 7 & - & - \\
110 & 125 & - & - & - & - \\
112 & 120 & 7 & 35 & - & - \\
119 & 280 & - & - & - & - \\
121 & 100 & 5 & 22 & - & - \\
\hline
\end{tabular}

3.5 knots, i.e. $1.75 \mathrm{~m} \mathrm{~s}^{-1}$. The actual distance (D) between two fish is therefore:

$$
D=\sqrt{ }\left[\left(x_{1}-x_{2}\right)^{2}+\left(y_{1}-y_{2}\right)^{2}+\left(\left(t_{2}-t_{1}\right) \times 1.75\right)^{2}\right]
$$

with $x$ and $y$ in metres and $t$ in seconds.

\section{Results}

\subsection{Anchovy}

The geostatistical results on the test series (Table 1) as well as on the whole images of the studied school (Table 2) showed that the anchovy schools examined in this study had broadly the same characteristics as those reported by Gerlotto et al. (2006). For the purposes of the present study, we concentrated on structures that were less than $10 \mathrm{~m}$ in approximate diameter. 

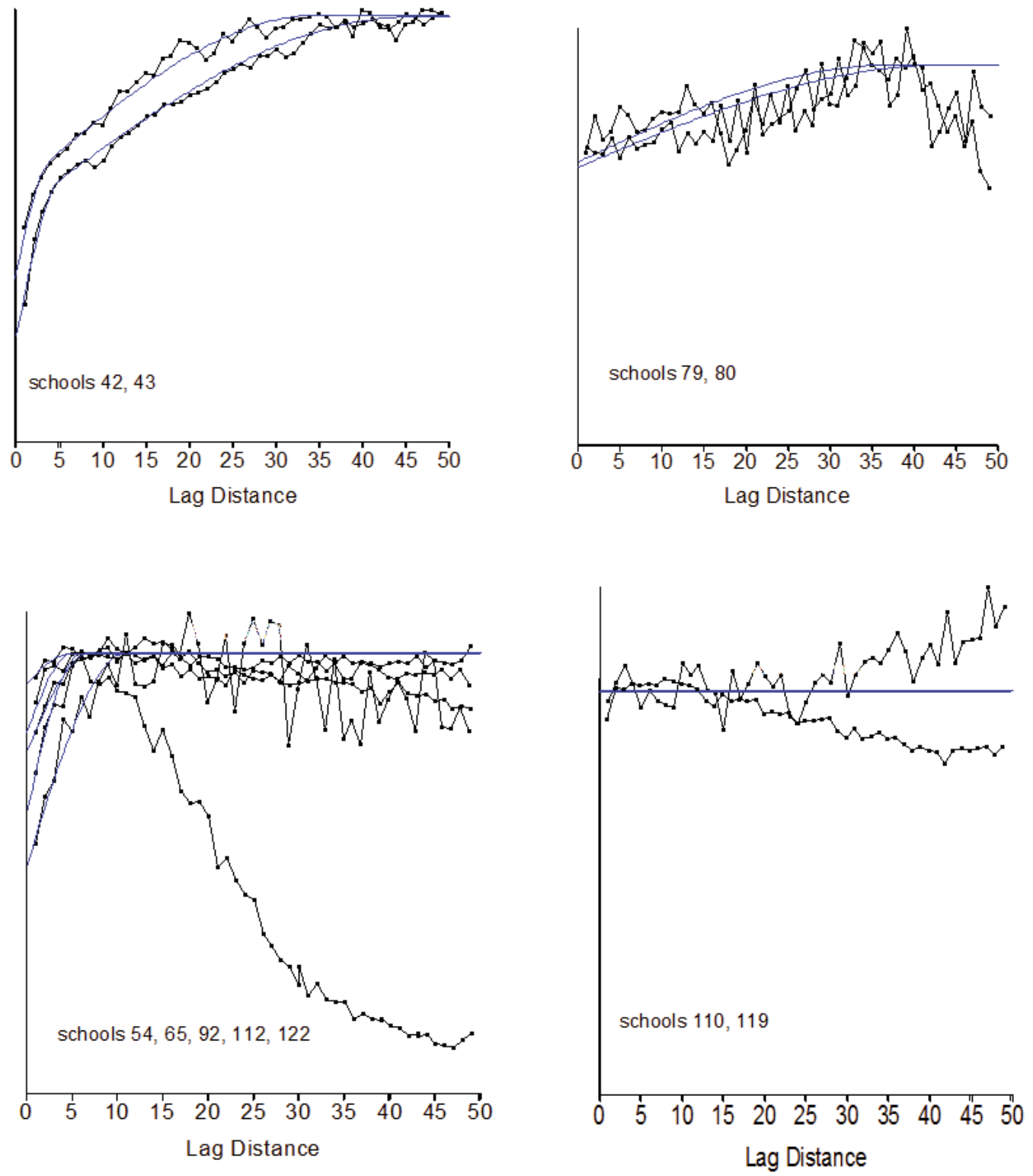

Fig. 3. Standardized variograms calculated on the test series of 11 schools. Lag distances in pixels $(1$ pixel $=0.1 \mathrm{~m})$

- School series (Table 1, Fig. 3)

At short range $(<10 \mathrm{~m})$, we identified two main structures in the series of schools. The first had a range of between 4 and 11 lags, with an average distance of 6.1 lags, i.e. $0.61 \mathrm{~m}$, appearing in 7 of the 11 schools. The second had a range of between 35 and 47 lags, i.e. a length of 3.5 to $4.7 \mathrm{~m}$. This "large" structure appeared in 4 of the 11 schools. Two schools displayed both the small and the large structure. Two schools displayed no structure, although the first points of the variogram were slightly lower than the others, however, Rivoirard et al. (2000) suggest that conclusions drawn from these first points in a variogram may be difficult to interpret.

- Images of school 149 (Table 2)

At short range $(<10 \mathrm{~m})$, we identified the same two main structures. The first had a range between 3 and 12 lags, with an average range of 7.5 lags, i.e. $0.75 \mathrm{~m}$, appearing in 14 of the 21 images measured. A series of experiments calculating variograms from the same image data at different thresholds were carried out in order to ensure that the choice of threshold did not introduce bias (Fig. 4). The results showed that this structure was not seen below a threshold of 10, implying that there was no structure inside the background noise. The structure observed with thresholds between 10 and 20 may be due to small groups of fish outside the main schools. These findings reinforced the conclusion that the observed small scale structures were not the result of a bias in the method, and probably have a biological origin. This conclusion is further supported by the results from the test series, where two of the 11 schools did not show obvious structure (schools 110 and 119, Table 1).

A second type of structure of between 20 and 45 lags, with an average distance of 28.6 lags, i.e. $2.8 \mathrm{~m}$, was also observed 
Table 2. Range (in lags) of the structures encountered in the $21 \mathrm{im}$ ages sampled in the studied school.

\begin{tabular}{ccccccc}
\hline & & \multicolumn{2}{c}{ Spherical 1 } & \multicolumn{2}{c}{ Spherical 2 } & \\
Image & Nugget & & & & \\
Nb & & & Linear \\
\cline { 3 - 5 } & & Range & Sill & Range & Sill & \\
\hline 13 & 350 & 8 & 35 & & & 1.7 \\
58 & 290 & 10 & 40 & & & 1.1 \\
129 & 180 & 3 & 10 & 30 & 45 & \\
134 & 160 & 5 & 15 & 25 & 20 & \\
173 & 210 & & & 40 & 30 & \\
207 & 230 & 6 & 35 & & & 1.0 \\
213 & 170 & 3 & 10 & 40 & 20 & 0.3 \\
221 & 95 & & & 25 & 5 & \\
236 & 200 & & & 25 & & \\
245 & 170 & 5 & 15 & 35 & 35 & \\
285 & 130 & & & 30 & 20 & \\
296 & 190 & 6 & 10 & 30 & 20 & \\
327 & 250 & 12 & 20 & & & 1.0 \\
336 & 140 & 4 & 18 & 20 & 10 & \\
367 & 265 & & & 20 & 20 & 1.1 \\
457 & 200 & 6 & 30 & & & 0.8 \\
465 & 130 & & & 20 & 30 & \\
496 & 220 & 5 & 20 & & & 1.1 \\
513 & 105 & 5 & 10 & 25 & 12 & 0.8 \\
540 & 210 & & & 35 & & \\
552 & 100 & 10 & 10 & 25 & 25 & \\
\hline
\end{tabular}

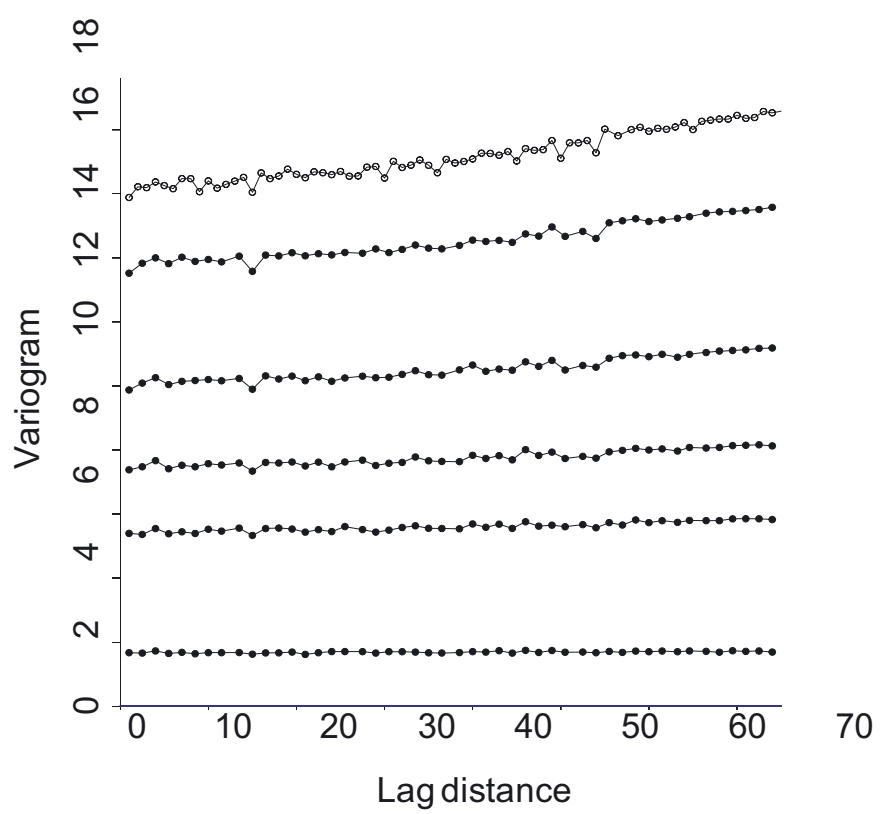

Fig. 4. Variograms calculated on image 496 for maximum thresholds at respectively (from top to bottom) 20, 18, 15, 12, 10, 5. Lag distance in pixels.

in the selected school, and at 40 lags for the test series, i.e. $4 \mathrm{~m}$ ). It appeared in 14 among the 21 images of the selected school, although not always in the same images as the smaller structure. Seven of the 21 images exhibited the two nested structures,

Seven had only the small one and seven had the large one. Unlike the schools in the test series, all the images that were sampled displayed at least one small-scale structure (Table 2, Fig. 5).

\subsection{Gadoids}

Histograms for arithmetical and log-transformed NND less than $15 \mathrm{~m}$ are presented (Fig. 5). The mean distance between individuals was $2.9 \mathrm{~m}$, and the modal value of arithmetical data was approximately $1 \mathrm{~m}$. This modal value would represent the "optimal neighbour distance" (OND) at which fish tend to adjust their distances to conspecifics. This mode disappears when data are log-normalized, but some "shoulder" remains at this value (Fig. 6). $\chi^{2}$ tests were calculated to check the fit between theoretical log-normal distribution and observed distributions for arithmetic and log-transformed NND data. The results show that the observed distributions are significantly different from the theoretical unimodal distributions (using only NND $<15 \mathrm{~m}$ ). For log-normalized data vs. theoretical distribution, $N=5388 ; \chi^{2}=233.6 ; d f=33 ; p=0.0000$.

The maximum interaction distance (MID) is difficult to evaluate and remains in large part speculative. One way to evaluate it is to apply a method developed by Petitgas (2003) and adapted by Soria (pers. comm.). The principle is to calculate the number of groups using an increasing MID as an exclusion criterion (a group represents an assemblage of 2 or more fish). For MID between 0 and $3 \mathrm{~m}$ the number of groups increased up to 1087; from 3 to $4 \mathrm{~m}$ the number of groups still increased but at a different rate. A MID of $3 \mathrm{~m}$ seemed to be a critical distance: it was the distance at which the number of groups of 2 fish began to decrease and the range of inflexion for the total number of groups. The maximum number of groups (1130) was observed for a MID of $4 \mathrm{~m}$ (Fig. 7).

For MID longer than $4 \mathrm{~m}$ the number of groups decreased, i.e. the many original groups successively merged until finally, they would form a single group for each tow. Using this result, we decided that the MID was around $3 \mathrm{~m}$, based on the shapes of the total histograms and the evolution of groupings. This suggests that at distances above $3 \mathrm{~m}$ fish did not display clear collective behaviour in the trawl mouth. We therefore used this value of $3 \mathrm{~m}$ as a criterion for separating fish entering in groups from the solitary fish in the FND data. From a total of 5466 fish caught and individualized, 3340 (61\%) were captured in groups and $2126(39 \%)$ were solitary. The 1087 groups counted ranged from 2 (640 groups) to 25 (1 group) fish. The average number of fish per group was 3.07.

\section{Discussion}

The spatial organisation of gregarious fish can be seen as an essential life pattern for these organisms. Their biology (Pitcher 2001) as well as their exploitation is based upon such structures (Reid 2000). It is therefore important to understand the way fish create and maintain these collective structures. Observing fish in the wild is not easy, and most of the intraschool organization studies have been performed in the laboratory (Svendsen et al. 2003). Looking for structure inside a free swimming school in the wild may seem almost impossible. There are numerous other influences that can blur the 

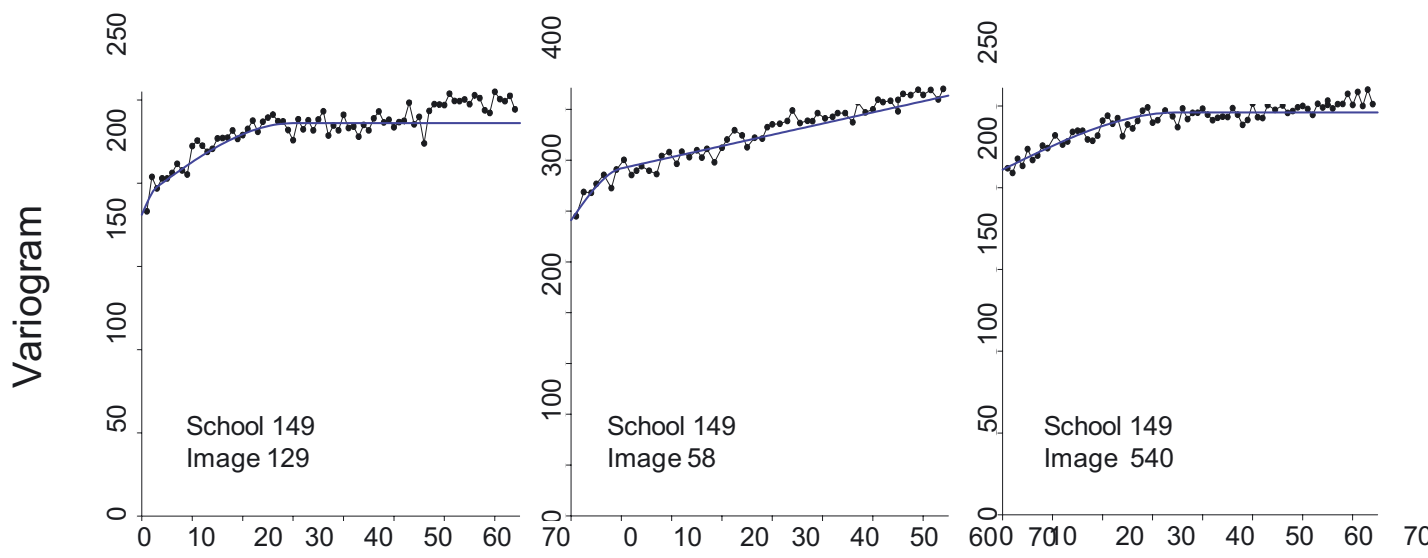

\section{Lag distance}

Fig. 5. Examples of structure distribution, with the variogram displaying one large structure (right, image 540), one small structure (centre, image 58) or two structures (left, image 129). Lag distance in pixels.
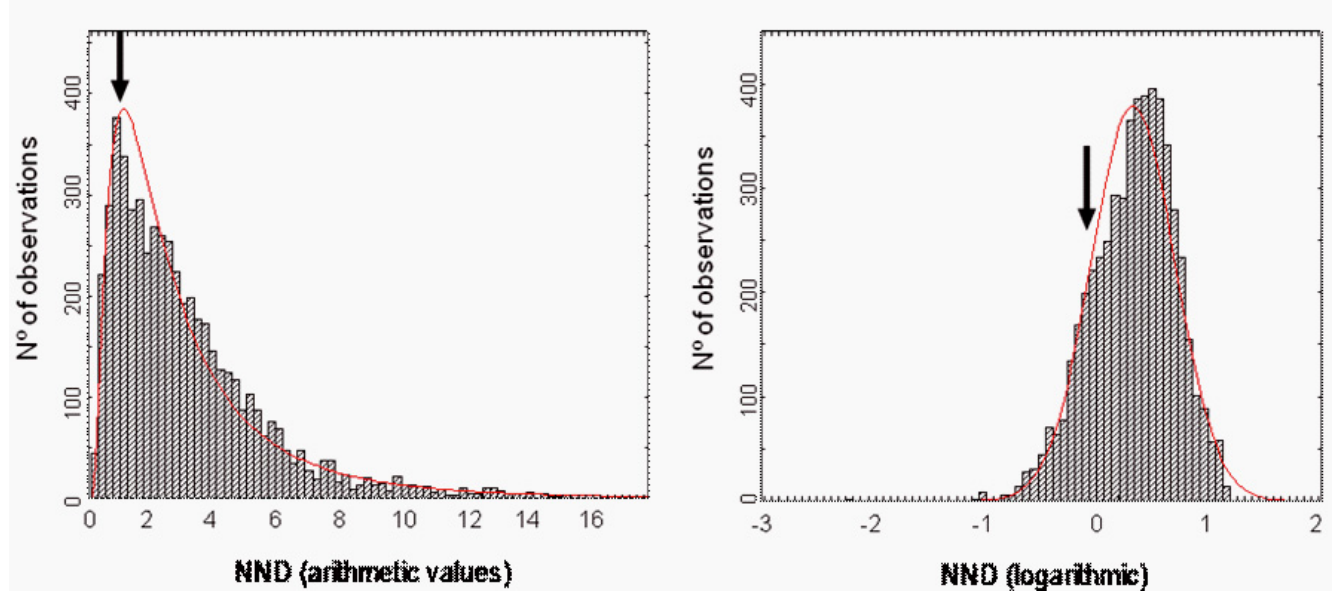

Fig. 6. Histograms of nearest neighbour distance (NND) - left: in arithmetic values; right: in logarithmic values - for fish seen in front of the GOV trawl. NND above $15 \mathrm{~m}$ have not been displayed on the histogram. Black arrows show the modal value from the arithmetic data. The adjusted curves for lognormal (left) and normal (right) theoretical distributions are displayed.

results, by introducing noise into the variable we are trying to measure. If one considers that an anchovy school is formed of tens of thousands of individuals, the idea of looking for groups of a few individuals using acoustics may appear even more unrealistic. However, we showed here for the first time that significant and unbiased small scale structure can be observed inside anchovy schools, and the characteristics of that structure determined. A major question was whether these structures were the result of the inter individual fish behaviour or due to some bias in the acoustic methods or the analytical approaches. This was explored by using comparative geostatistical measurements on the fish echoes and on the background noise. The conclusion was the structures were observed only with schooling fish present. For anchovy these data clearly demonstrate the existence of micro-structures within schools, and hence, a characteristic small scale aggregative behaviour.

The conclusions derived from the analysis of the North Sea mixed gadoids observed in the mouth of a trawl were obviously somewhat more speculative. The situation was far from natural, and a series of stimuli would be expected to interfere with the natural distribution patterns (Harden-Jones 1963; Wardle 1983; Godø et al. 1999). Besides, gadoids are not "obligatory" gregarious fish, unlike anchovy, and can display solitary behaviour. These results must be considered as an exercise in the feasibility of measuring NND in aggregations of large fish rather than as behavioural results per se. We will not draw any conclusion on the existence of micro-structures in gadoids, although it is clear that such research on microstructures using multibeam sonar can be done through adapted experiments.

This work is one of a number of results from various research approaches which reinforce the hypothesis of microgroups and these are worth discussing in more detail here. Tagging has been used for decades to study the migration patterns of fish. Some intriguing results have been repeatedly obtained where fish caught and tagged at the same time, were re-captured together, sometimes more than a year later (e.g. Konstantinov 1961; Konstantinov and Ponomarenko 1960). 


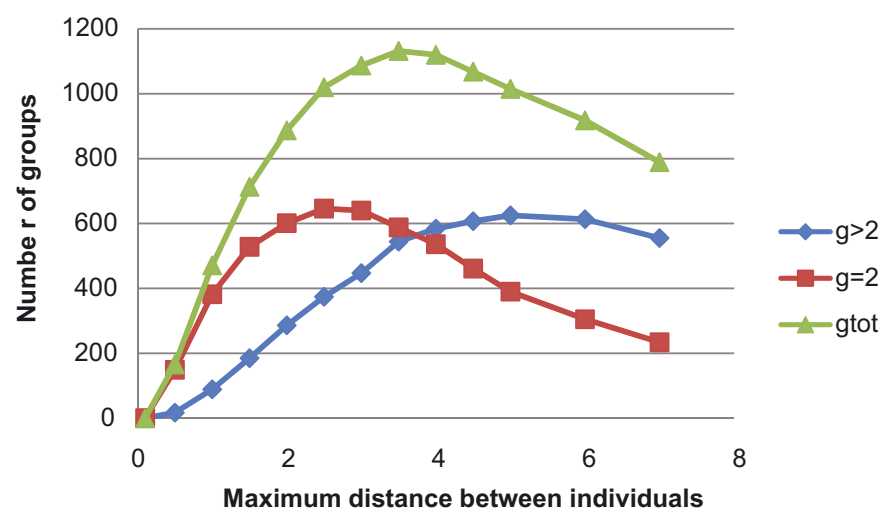

Fig. 7. Evolution of the number of structures according to the selected maximum interaction distance (MID, in metres). Squares: number of groups of 2 fish; diamonds: number of groups of more than 2 fish; triangles: number total of groups.

More recently, Hay and McKinnell (2002) showed that some shoal fidelity can be concluded for Pacific herring (Clupea pallasi), and Kimley and Holloway (1999) found the same result for tuna tagging experiments. Dagorn et al. (2007) tagged tuna concentrated under fish aggregative devices (FADs) and found that groups of tunas left and joined a given FAD together: familiarity was one possible explanation for these results. The question remains as to whether this familiarity is related to a school or to a smaller group (micro-group). Radakov (1973) argued that schools could not last months or years, and showed with his own experiments that schools were permanently in phases of splitting and gathering. Soria (1994) found similar results for schools of Harengula sp. in Martinique, where aerial observations on schools suffering predation by tunas showed that they could be split into several parts. Gerlotto et al. (2006) drew the same conclusion from observations on anchovy in Peru suffering high predation by sea lions, no school could be individualized for more than a few minutes. One of the most likely hypotheses that can encompass these two phenomena (long duration of individual associations and short duration of schools) is the possible mechanism of microgroups of fish that are familiar with each other, and which could be more stable than large associations.

One of the major outcomes of all these studies is that inter individual familiarity may exist among fish. This was tested through laboratory experiments, and for example, Griffiths and Magurran (1997) showed that after being isolated for a few days, a group of 6 fish (guppies) maintained their cohesion as a group, even when placed in a larger aquarium with a high number of conspecifics. Recent research into the cognitive behaviour of certain species such as salmon points to the evidence that fish can distinguish and prefer familiar individuals (Griffiths and Ward 2007). Studies of reproductive behaviour indicate that mating is not simply a collective behaviour triggered for all the individuals by some hormone or pheromone release, but is a complex process, where schools often display different shapes and behaviour compared to non-reproductive periods (Axelsen et al. 2000).

Gerlotto et al. (2006) hypothesized that transmission of anti-predator signals inside schools of anchovy, seen as waves of agitation, may not function properly unless a number of conditions are satisfied, e.g.:

- the existence of preliminary information on the presence of predators before fish can see them,

- the existence of fish that have already experienced the predation (Soria et al. 1993),

- the collective reaction of a group of individuals reinforcing the signal.

The learning process might be expected to be more effective if micro-groups were present and persisted for some time.

To synthesize, a series of proposals for the existence of these "small world networks" are given in the literature that we can broadly gather into two types. On the one hand there is a "comfort" rationale, by allowing an individual to decrease its attention level when surrounded with familiars. On the other hand interactions with familiars may allow the individuals to benefit from the experience of others and may improve the learning process e.g. for recognising predators, acquiring spatial knowledge, etc. This latter proposal would agree with the suggestion that individuals could benefit "with avoiding many of the costs thought to be associated with individual learning, such as making mistakes or wasting time" (Odling-Smee et al. 2006). It is likely that when a micro-group leaves a school to enter in another one, which might happen frequently, e.g. during the break up of a school under predation (Fréon et al. 1996), it may also transmit the knowledge obtained inside the first one to the second one (Soria et al. 1993). We can see that if the micro-structures that we have observed and measured can be confirmed as genuine micro-groups through behavioural experiments, this perception could change our understanding of the functioning of schools. They may not be simple spatially organized collective structures but could also be venues for exchange of information between non-anonymous individuals, facilitating adaptation to a changing world.

\section{Conclusion}

Using acoustic devices, we have observed the existence of micro-structures in pelagic schools. Two questions remain: how long do these micro-structures last? Do individuals inside these structures develop some familiarity and fidelity to the group? The use of conventional acoustics alone will not allow further progress on small pelagic fish, as individuals cannot be identified. In the case of larger fish, we showed that 3D location of individuals could be obtained, and their spatial inter-relationships determined in detail. Observing fish in a trawl haul is almost certainly not the best way to study their behaviour. However if we were able to deploy the sonar in a vertical position above or below an area where individuals are present, any natural aggregative behaviour could then be observed. To study the duration of the micro-groups, other methods will be needed and acoustic tagging is likely to be the best method for observing and maintaining contact with numbers of individuals. Simultaneous observation of the whole aggregation using multibeam sonar can help to see individual patterns within the context of the school. Laboratory experiments remain very important to examine these questions. Finally the inclusion in IBM of rules based on the micro-group hypothesis would be very valuable to explore the ramifications of this new perception. 


\section{References}

Axelsen B.J., Nøttestad L., Fernø A., Johannessen A., Misund O.A., 2000, "Await in the pelagic": dynamic trade-off between reproduction and survival within a herring school splitting vertically during spawning. Mar. Ecol. Prog. Ser. 205, 259-269.

Ballerini M., Cabibbo N., Candelier R., Cavagna A., Cisbani E., Giardina I., Lecomte V., Orlandi A., Parisi G., Procaccini A., Viale M., Zdravkovic V., 2008, Interaction ruling animal collective behavior depends on topological rather than metric distance: evidence from a field study. Proc. Nat. Acad. Sci. USA $105,1232-1237$.

Bertrand A., Gerlotto F., Bertrand S., Gutiérrez M., Alza L., Chipollini A., Díaz E., Espinoza P., Ledesma J., Quesquén R., Peraltilla S., Chavez F., 2008, Schooling behaviour and environmental forcing in relation to anchoveta distribution: an analysis across multiple spatial scales. Prog. Oceanogr. 79, 264-277.

Brown C., Laland K., Krause J., 2006, Fish cognition and behaviour. Blackwell, Fish and Aquatic Resources Series $N^{\circ} 11$.

Couzin I.D., Krause J., James R., Ruxton G.D., Franks N.R., 2002, Collective memory and spatial sorting in animal groups. J. Theor. Biol. 218, 1-11.

Dagorn L., Holland, K.N., Itano, D.G., 2007, Behavior of yellowfin (Thunnus albacares) and bigeye (T. obesus) tuna in a network of fish aggregating devices (FADs). Mar. Biol. 151, 595-606.

Fréon P., Gerlotto F., Soria M., 1992, Changes in school structure according to external stimuli: description and influence on acoustic assessment. Fish. Res. 15, 45-66.

Fréon P., Gerlotto F., Soria, M. 1996, Diel variability of school structures with special reference to transition periods. ICES J. Mar. Sci. 53, 459-464.

Gerlotto F., Soria M., Fréon, P., 1999, From two dimensions to three: the use of multibeam sonar for a new approach in fisheries acoustics. Can. J. Fish. Aquat. Sci. 56, 6-12.

Gerlotto F., Paramo J., 2003, The three-dimensional morphology and internal structure of clupeid schools as observed using vertical scanning multibeam sonar. Aquat. Living Resour. 16, 113-122.

Gerlotto F., Bertrand S., Bez N., Gutierrez M., 2006, Waves of agitation inside anchovy schools observed with multibeam sonar: a way to transmit information in response to predation. ICES J. Mar. Sci. 63, 1405-1417.

Godø O.R., Walsh S.J., Engås A., 1999, Investigating density dependent catchability in bottom trawl surveys. ICES J. Mar. Sci. 56, 292-298.

Griffiths S.V., Magurran A. E., 1997, Familiarity in schooling fish: how long does it take to acquire? Animal Behav. 53, 945-949.

Griffiths S.W., Ward A., 2006, Learned recognition of conspecifics. In: Brown C., Laland K., Krause J. (Eds.) Fish cognition and behaviour (Chapter 8), Blackwell, Fish and Aquatic Resources Series $N^{\circ} 11$, pp. 139-165.

Harden-Jones F.R., 1963, The reaction of fish to moving backgrounds. J. Exp. Biol. 40, 437-446.

Hay D.E., McKinnell S.M., 2002, Tagging along: association among individual Pacific herring (Clupea pallasi) revealed by tagging. Canadian Journal of Fisheries and Aquatic Sciences, 58 19601968.

Huth A, Wissel C., 1992, The simulation of the movement of fish schools. J. Theor. Biol. 156, 365-385.

Jones E.G., Copland P.J., Reid D.G., 2001, Combined acoustic and video observations of fish behaviour in a survey trawl. Report of the Joint Session of the Working Groups on Fisheries Acoustics Science (WGFAST) and Technology (WGFAST) and Fishing Technology and Fish Behaviour (WGFTFB), pp. 4-5. ICES CM 2001/B: 04, 15p.

Kimley A.P., Holloway C.F., 1999, School fidelity and homing synchronicity of yellowfin tuna, Thunnus albacares. Mar. Biol. 133, 307-317.

Konstantinov K.G., 1961, Tagging demersal fish in the Barents Sea. Voprosy Ikhtiologii 1, 1-19.

Konstantinov K.G., Ponomarenko V.P., 1960, Prolonged group movements of Barentz Sea cod according to tagging data. Trudy Murmanskogo Morskogo Biologicheskogo Instituta 2, $\mathrm{N}^{\circ} 6$.

Mirabet V., Auger P., Lett C., 2007, Spatial structures in simulations of animal grouping. Ecol. Model. 201, 468-476.

Odling-Smee L., Simpson S.D., Braithwaite V.A., 2006, The role of learning in fish orientation. In: Brown C., Laland K., Krause J. (Eds.) Fish cognition and behaviour (Chapter 7). Blackwell, Fish and Aquatic Resources Series $\mathrm{N}^{\circ} 11$.

Parrish J.K., Edelstein-Keshet L., 1999, Complexity, pattern, and evolutionary trade-offs in animal aggregation. Science 284, 99-101.

Parrish J.K., Viscido S.V., Grunbaum D., 2002, Self-organized fish schools: an examination of emergent properties. Biol. Bull. 202, 296-305.

Petitgas P., 2003, A method for the identification and characterization of clusters of schools along the transect lines of fisheries-acoustic surveys. ICES J. Mar. Sci. 60, 872-884.

Pitcher T.J., 2001, Fish schooling. Encyclopedia of Ocean Sciences, Vol. 2 (D-H), pp. 975-987.

Radakov D.V., 1973, Schooling in the Ecology of Fish. Wiley, New York.

Reid D.G. (Ed.), 2000, Report on echo trace classification. ICES Coop. Res. Rep. $\mathrm{N}^{\circ} 238$.

Rivoirard J., Simmonds J., Foote K.G., Fernandes P., Bez, N., 2000, Geostatistics for Estimating Fish Abundance. Blackwell Science, Oxford.

Soria M., 1994, Structure et stabilité des bancs et agrégations de poissons pélagiques côtiers tropicaux: applications halieutiques. Thèse Dr Univ. Rennes 1.

Soria M., Gerlotto F., Fréon P., 1993, Study of learning capabilities of a tropical clupeoids using an artificial stimulus. ICES Mar. Sci. Symp. 196, 17-20.

Soria M., Fréon P., Chabanet P., 2007, Schooling properties of an obligate and a facultative fish species. J. Fish Biol. 71, $1257-$ 1269.

Svendsen J.C., Skov J.B., Bildsoe M., Steffensen J.F., 2003, Intraschool positional preference and reduced tail-beat frequency in trailing position in schooling roach under experimental conditions. J. Fish Biol. 62, 834-846.

Vabø R., Nøttestad L., 1997, An individual-based model of fishschool reactions: predicting antipredator behaviour as observed in nature. Fish. Oceanogr. 6, 155-171.

Viscido S.V., Parrish J. K., Grunbaum D., 2005, The effect of population size and number of influential neighbors on the emergent properties of fish schools. Ecol. Model. 183, 347-363.

Wardle C.S., 1983, Fish reaction to towed fishing gears. In: MacDonald A.G., Priede I.G. (Eds.). Experimental biology at sea. Academic Press, London, pp. 167-195.

Zaferman M., 2005, Fine structure of fish aggregation: methods of study, effect on acoustic characteristics and fishing-gear catchability. ICES Doc. CM/2005/U: 13. 